Document downloaded from:

http://hdl.handle.net/10251/99447

This paper must be cited as:

J. Antonino-Daviu; Riera-Guasp, M.; Pons Llinares, J.; José Roger-Folch; Perez, R.; Charlton-Perez, C. (2012). Toward condition monitoring of damper windings in synchronous motors via EMD analysis. IEEE Transactions on Energy Conversion. 27(2):432-439. doi:10.1109/TEC.2012.2190292

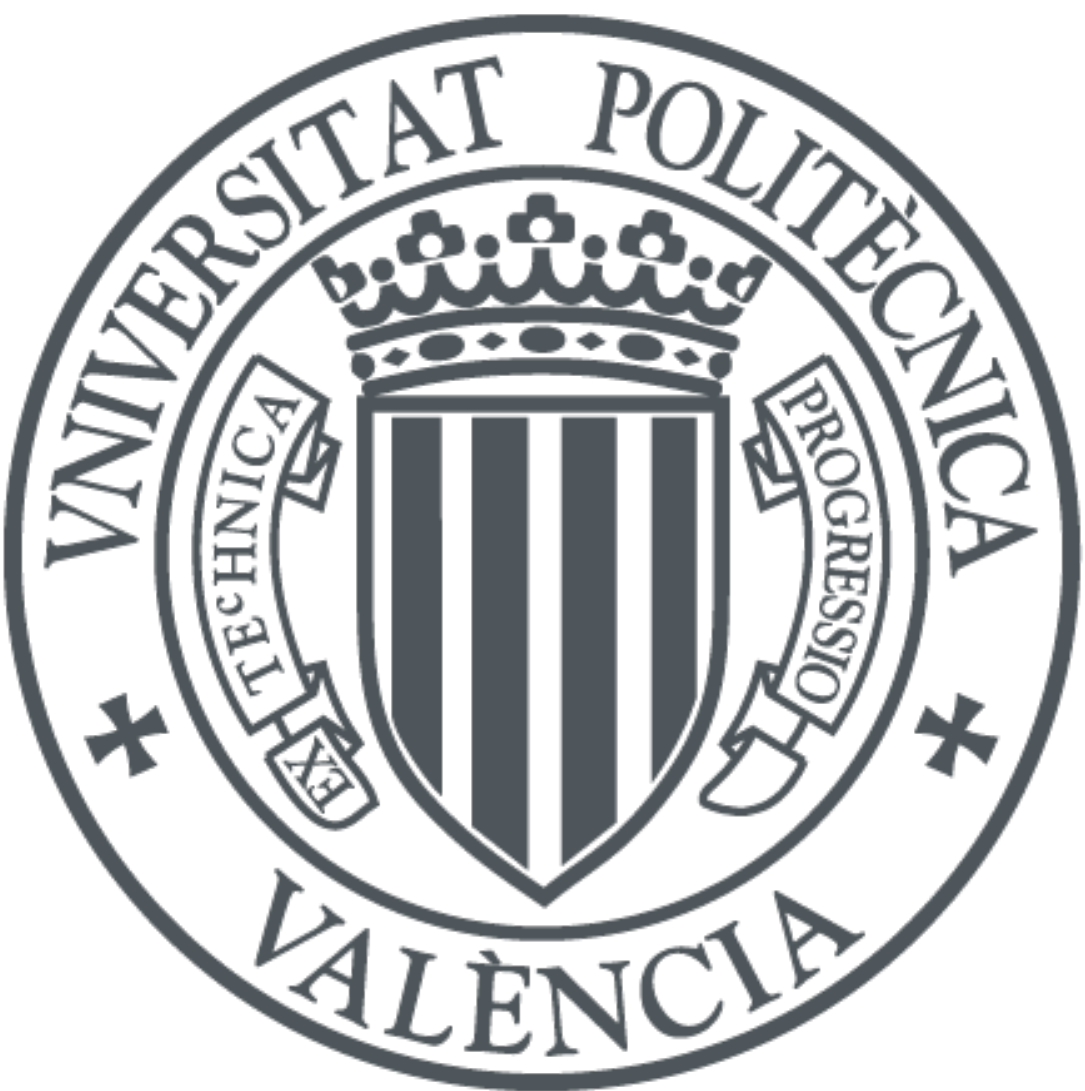

The final publication is available at

http://doi.org/10.1109/TEC.2012.2190292

Copyright IEEE-INST ELECTRICAL ELECTRONICS ENGINEERS INC

Additional Information 


\title{
Towards condition monitoring of damper windings in synchronous motors via EMD analysis
}

\author{
J. A. Antonino-Daviu, M. Riera-Guasp, J. Pons-Llinares, J. Roger-Folch, R.B. Pérez and C. Charlton-Pérez
}

\begin{abstract}
Failures in damper windings of synchronous machines operating in real facilities have been recently reported by several authors and companies. These windings are crucial elements of synchronous motors and generators, playing an important role in the asynchronous startup of these machines as well as in their stability during load transients. However, the diagnosis of failures in such elements has barely been studied in the literature. This paper presents a method to diagnose the condition of damper bars in synchronous motors. It is based on the capture of the stator current of the machine during a direct startup and its further analysis in order to track the characteristic transient evolution of a particular fault-related component in the time-frequency map. The fact that the damper only carries significant current during the startup and little or no current, when the machine operates in steady-state, makes this transient-based approach specially suited for the detection of such failure. The Hilbert-Huang Transform (based on the Empirical Mode Decomposition (EMD) Method) is proposed as a signal processing tool. Simulation and experimental results on laboratory synchronous machines prove the validity of the approach for condition monitoring of such windings.
\end{abstract}

Index Terms-synchronous motors, damper windings, transient analysis, Hilbert-Huang transform, condition monitoring.

\section{INTRODUCTION}

S ynchronous motors are less used than other electric motors in industry due to their more complex construction and maintenance, their stability problems or the necessity of auxiliary systems enabling their startup from standstill, among other reasons. Nonetheless, they are a very interesting alternative in many industrial applications due to their inherent properties [1].

There are several methods for startup of synchronous motors. For large machines, it is rather common to use a damper winding (also known as an amortisseur winding),

Manuscript received August 23, 2011. This work was supported by the Spanish Ministerio de Ciencia e Innovación (MICINN) in the framework of the VI Plan Nacional de Investigación Científica, Desarrollo e Innovación Tecnológica 2008-2011.(Programa Nacional de proyectos de Investigación Fundamental, project reference DPI2011-23740)

J.A. Antonino-Daviu, M. Riera-Guasp, J. Pons-Llinares and J. RogerFolch are with the Instituto de Ingeniería Energética, Universidad Politécnica de Valencia, Camino de Vera s/n, 46022, Valencia, SPAIN (phone: 0034963877592; fax: 0034-963877599; e-mail: joanda@die.upv.es).

R.B. Perez is with the Department of Nuclear Engineering, University of Tennessee, Knoxville, TN, USA (e-mail: rperez1@utk.edu)

C. Charlton-Pérez is with the Robinson Court, Reading, RG6 5YX, UNITED KINGDOM (e-mail: cristina.l.perez@ gmail.com) incorporated in the rotor. These windings consist of aluminum or copper bars, which are inserted axially into pole face slots and connected at the ends in such a way that a complete winding similar to the squirrel cage of an asynchronous motor is obtained [2]. The main function of these damper bars is to produce enough motor torque when the machine is started from standstill, while a three phase alternating voltage is applied to the armature terminals. Through selecting a proper rotor bar material, the torque can be fixed in order to start the motor reasonably well, even with an inertia load [2]. Hence, thanks to the damper windings, synchronous machines can be started direct-on-line, just as with asynchronous machines.

Despite the design of damper windings taking into consideration both current and thermal stresses during their operation [3], eventual failure is possible, due to reasons such as deficient construction of the damper cage [4] or frequent and hard duty cycles (excessive start-stop cycles or frequent speed changes [5-7]). The probability of occurrence of such a failure may be not high in some applications [6], its presence has been confirmed by other authors and companies in other synchronous machines operating in real facilities: small salient-pole machines [7], hydro-generators $[8,10]$ and single phase machines [9].

Nevertheless, so far, few papers have dealt with the monitoring of the condition of such elements in synchronous machines. In [6], a study of broken damper bars in large salient-pole synchronous machines suggesting a flux analysis was presented; this technique required the installation of an additional flux sensor in the machine. [7] proposed a method for diagnosing rotor faults (and among them, broken damper bars) through the identification of particular frequency components in the Fourier spectrum of the steady-state current. However, this technique did not distinguish between the frequency components due to broken bars and those caused by other types of faults such as eccentricities. Also, there is the constraint that the current in the damper when the machine rotates at synchronous speed is zero. [4] proposed a method for the diagnosis of the fault based on the measurement of pole voltage differences in the field winding, which, as the authors admit, did not enable the monitoring of all damper bars. Other authors [5, 11-12] presented various synchronous machine models, which were able to simulate the presence of the aforementioned fault.

The present work proposes an alternative approach for diagnosing broken damper bars in synchronous motors, which 
showed satisfactory results when applied to rotor condition monitoring of squirrel cage induction motors [13-15]. Unlike some of the aforementioned techniques, the proposed method relies on the analysis of the current, which is a quantity easily measured in a non-invasive way. More concretely, the considered current is the stator current demanded by the machine during the motor startup transient, that is, when the damper is carrying appreciable current and the machine behaves as if it was asynchronous. Then, this non-stationary current waveform is analyzed by proper Time-Frequency Decomposition (TFD) tools, in order to track the characteristic transient evolutions of specific fault-related components, which lead to characteristic patterns constituting reliable indicators of the fault, even in no-load conditions [13]. Furthermore, these patterns serve as a basis for the development of parameters in order to quantify the level of failure in the machine.

Different TFD tools have been applied in the literature for analyzing quantities with a time-varying frequency spectrum: Undecimated Discrete Wavelet Transform (UDWT) [16], Discrete Wavelet Transform (DWT) [13-15, 17-20], Continuous Wavelet Transform (CWT) [21-23], Hilbert Transform (HT), Hilbert-Huang Transform (HHT) [24-26], Wigner-Ville (WVD) and Choi-Williams Distributions (CWD) [27-28]...In this paper, the HHT is used. The main reason is that it is a cutting-edge tool enabling a clear extraction of the transient evolution of low-frequency fault-related harmonics with rather low computational requirements. Furthermore, the fault-related patterns are extracted in a twofold way; through the characteristic waveforms raising in the intrinsic mode functions (imf's) resulting from the HHT and through the 2-D or 3-D time-frequency representations provided by the HilbertHuang Spectra of these imf's.

It must be remarked that an interesting related method for detection of damper breakages was patented in 1991 by Prof. G.B. Kliman [29]. However, the invention presented there was focused on the computation of the amplitude modulation of the startup current waveform, rather than analyzing the frequency evolution of fault-related components - this is understandable when taking into account the absence of proper TFD tools when that patent was presented.

In summary, the method proposed here implies the following advantages versus previously published works:

- For the first time, a non-invasive transient-based methodology is proposed for diagnosing the condition of damper bars in synchronous motors.

- It is especially suited for damper windings diagnosis, taking advantage of the fact that these elements only carry significant currents during the startup of the machine.

- The validity of the method is proven by real data coming both from simulations and laboratory synchronous machines.

- For the first time, new quantification indicators based on the imf's resulting from the HHT are proposed. They may lead to higher sensitivities due to the claimed more accurate representation of fault-related components achieved with this transform, in comparison with other TFD tools [24].

- The method proposed in the present paper might provide significant additional information enabling the diagnosis of the failure even if other faults or phenomena are present in the machine [13-15].

\section{PHYSICAL FACTS}

The damper winding of a synchronous machine can be assimilated to the rotor cage of an induction motor. For induction machines, a widespread theory for the study of the rotor bar breakage phenomenon was proposed by W. Deleroi [30]. According to this theory, the effect of a broken bar can be studied considering the superposition of two different configurations: first, the machine in healthy condition (Fig.1 (b)) plus, second, the machine with a current source in the broken bar (fault current) (Fig. 1 (c)) [15]. This fault current is equal to the current flowing through the same bar in the healthy machine but in the opposite direction so that, when adding both configurations, the total current through the bar is zero (Fig. 1(a)). The fault current flows through the shortcircuit rings and the rest of cage bars, originating a magnetic field in the air gap (fault field, $B_{\text {Fault }}$ ). The spatial waveform of the air-gap flux density $B_{\text {Fault }}(\alpha, t)$ caused by the fault field is a stepped bipolar wave, whose amplitude and spectral composition cyclically changes with time. Fig. 2 represents, in a qualitative way, the configuration of the spatial flux density waveform caused by the fault field at a certain time, for the case of a machine with 9 bars. Rigorous characterization of this field can be found in [15].

As commented in [15], the spatial wave $B_{\text {Fault }}(\alpha, t)$ can be decomposed as the sum of spatial harmonics with $1,2,3, \ldots$, $p, \ldots, n$ pole pairs; these harmonics have a fixed position with respect to the rotor, but their amplitudes oscillate proportionally with the fault (or rotor) current. The application of the Leblanc's theorem to every harmonic field leads to two series of rotating components with constant amplitude and speed are obtained: a series with the same rotating direction as the rotor (+) and another series with the opposite direction (-).

The fault field caused by the breakage, which is superimposed on the normal field of the healthy machine, leads to alterations in its behavior; more specifically, it induces several current harmonics in the stator windings. The detection of these harmonics in the Fourier spectrum of the steady-state current is the basis of the classical method for the bar breakage diagnosis in induction motors (Motor Current Signature Analysis, MCSA) [31-32].

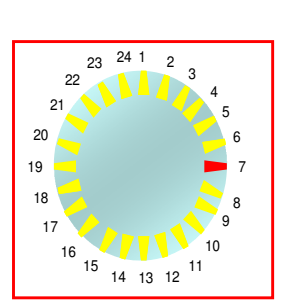

(a)

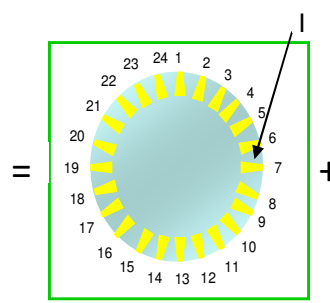

(b)

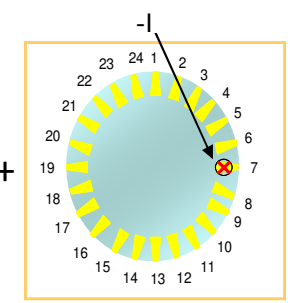

(c)
Fig. 1. Approach proposed by [18]: (a) machine with one broken bar= (b) healthy machine + (c) machine with current source with value $-\mathrm{I}$ in the bar that breaks. 


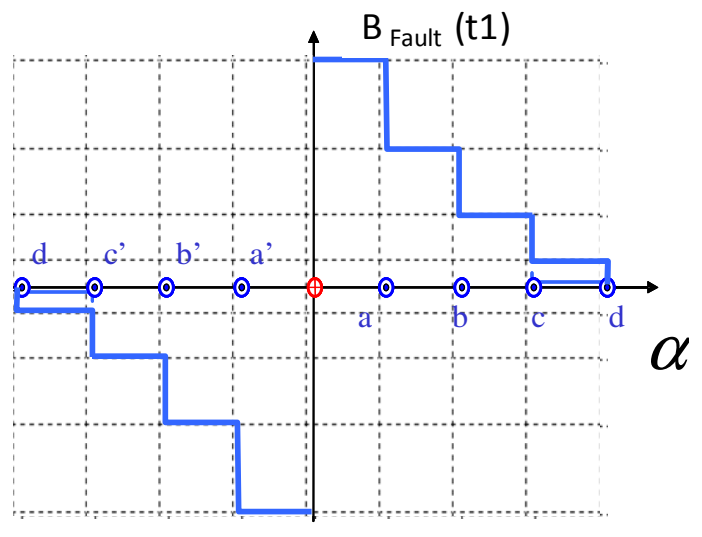

Fig. 2. Air-gap flux density waveform created by the fault field at $\mathrm{t} 1$.

The frequency components induced by the fault field in the stator current are given by (1) [33], with $s, f$ and $p$ being the slip, the supply frequency and the number of pole pairs, respectively. The components induced by the fault field lead to oscillations in the rotor speed, originating a new family of fault related components [34-35], with frequencies given by (2). In the industry, the most usual components for the diagnosis of rotor asymmetries are the main sideband components, which appear around $f$. These components are given by (3) (lower sideband -negative sign- and upper sideband -positive sign-) [14].

$$
\begin{gathered}
f_{b}=\left(\frac{k}{p}(1-s) \pm s\right) \cdot f \quad \frac{k}{p}=1,3,5 \ldots . \\
f_{b}=(1 \pm 2 \cdot k \cdot s) \cdot f \quad k=1,2,3 \ldots \\
f_{s b}=(1 \pm 2 \cdot s) \cdot f
\end{gathered}
$$

Following an equivalent approach, a broken damper bar in a synchronous motor changes the original damper cage current distribution in the machine [4]. A fault field - or 'interference field' as named by Bacher [4] - caused by the damper breakage also appears in this case. Nonetheless, in synchronous machines, the damper cage carries only appreciable current during the 'asynchronous' startup and during transient oscillations with respect to the synchronous speed. It carries no current when the machine operates in strict steady-state, while it rotates at synchronous speed [31]. Therefore, the induced harmonics caused by cracked damper bars will be only significant during transient operation, providing an interesting basis for implementation of damper fault detection techniques.

Analogously to what happens in induction motors, when the synchronous motor is started direct-online, by the action of the damper winding, the slip $s$ drops from 1 (when the machine is first connected) to 0 (when the startup is finished, just before synchronization). Therefore, the frequencies of the most prominent fault-related components, given by expression (3), will also change. More specifically, the frequency of the lower sideband component (LSC) will change between the supply frequency $f(=50 \mathrm{~Hz}$ in our case) (when $s=1), 0 \mathrm{~Hz}(s=1 / 2)$ and again $f \mathrm{~Hz}(s \approx 0)$. This variation leads to a characteristic 'signature' in the time-frequency map which constitutes a reliable indicator for the diagnosis of the broken damper bar. Fig. 3 (a) shows the theoretical waveform corresponding to the evolution of the LSC (already justified in [15]). Fig. 3 (b) depicts the characteristic frequency variation of this component, which was obtained from simulated startup speed data for a three-phase synchronous machine with $p=2$.

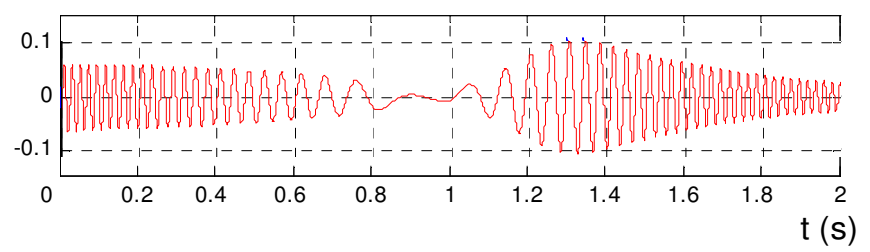

(a)

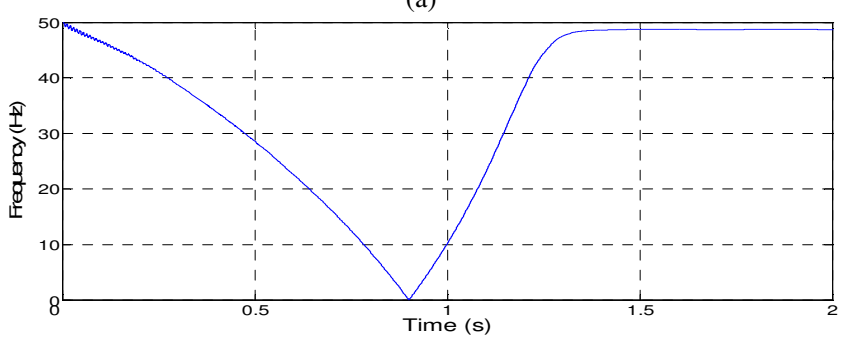

(b)

Fig. 3. (a) Theoretical waveform of the LSC during the startup; (b) Predicted time-frequency evolution during startup for the LSC.

\section{HILBERT-HUANG TRANSFORM FOR LSC EXTRACTION}

The HHT was introduced by N.E. Huang [36-37]. It is based on the decomposition of a signal in terms of empirical modes (Empirical Mode Decomposition, EMD) and on their representation within the context of the Complex Trace Method (CTM), formerly introduced by Gabor [38].

For multi-component, noise corrupted signals the CTM fails because the Hilbert transform processing of those noisy waves generates spurious amplitudes at negative frequencies. Huang [36-37] developed a novel signal analysis approach to avoid generating unphysical results. In order to do this, the Hilbert transform is not directly applied to the signal itself but to each of the members of an empirical decomposition of the signal into intrinsic mode functions (imf's).

The algorithm to create the imf's, known as "sifting", is simple: Given a certain signal $X(q)$ ( $q$ representing either time or an spatial coordinate), first, the local extrema of the data are identified and used to create upper and lower envelopes which enclose the signal completely. From this envelope, a running mean is created. By subtracting this "mean" from the data, one obtains a new function, which must have the same number of zero crossings and extrema (i.e. it exhibits symmetry across the $q$-axis). If the function constructed in this way does not satisfy this criterion, then the "sifting" process continues until some acceptable tolerance is reached [36]. The resulting $q$-series is the first 'imf', c1(q), and contains the highest frequency oscillations found in the data (the shortest time scales). Imf1, 
is then subtracted from the original data, and this difference is taken as if it were the original signal. Then, the sifting process is applied again to the new signal

The procedure of finding modes, $c_{j}(q)$, continues until the last mode, the residue $R_{n}$, is found. This will contain the trend (i.e., the "time -varying" mean). Hence, the signal, $X(q)$, is given by the sum:

$$
X(q)=\sum_{j=1}^{n} c_{j}(q)+R_{n}
$$

In [36], the completeness and orthogonality of the imfexpansion are discussed in detail. Fig. 4 shows the basic scheme of the EMD.

The application of the Hilbert transform to a given intrinsic mode function, imf, generates a $q$-frequency plot, the HilbertHuang $(H H)$ spectrum, $H(\omega, q)$, where $\omega$ is the instantaneous frequency [24]. Furthermore, the marginal spectrum can be also defined according to (5), where $Q$ is the total data length [39];

$$
h(w)=\int_{0}^{Q} H(w, q) \cdot d q
$$

While the $\mathrm{HH}$ spectrum offers a measure of the amplitude contribution for each frequency and time, the marginal spectrum (power spectral density) is a measure of the total amplitude (or energy) contribution from each frequency [39].

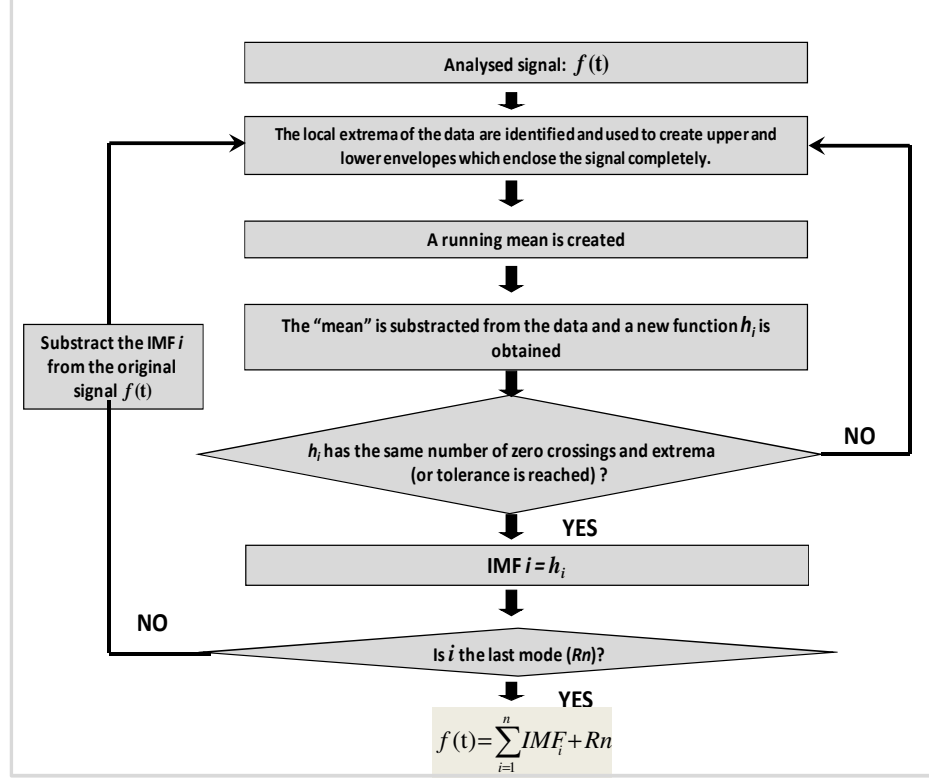

Fig.4. Basic scheme of EMD algorithm.

\section{RESULTS}

Both simulated and experimental signals were used for validating the proposed EMD-based diagnosis methodology. Simulations were carried out by using a simplified synchronous machine model implemented in MATLAB based on a novel technique to calculation of inductances [40]. On the other hand, experimental tests were developed with two industrial synchronous machines. They were cylindrical rotor 4-pole machines which were started direct on-line as if they were asynchronous motors by using their damper cage (see experimental test bed in Fig. 5) and without feeding their excitation winding. Once the speed was near the synchronous speed, the excitation winding was supplied and the machine synchronized. The synchronous machine was loaded with a DC machine coupled in the same shaft (see Figure 5).

The damper cage was based on 36 copper bars, each with a diameter of $4 \mathrm{~mm}$. Detailed characteristics of each machine are specified in Table I. One of the machines (machine 1) had a significantly damaged damper cage; the damper asymmetry was forced during previous experimentation by cracking the damper bars by using a drill, welding them again afterwards. The other synchronous machine (machine 2) had a damper with a low level of asymmetry caused by its fabrication process and operation during years.

In all the tests, the phase startup currents of the synchronous motors started with the damper were registered by using a digital oscilloscope. Afterwards, the HHT of the startup current was computed for each case considering two imfs (imf1 and imf2). In all the analyses, imf1 includes only the fundamental component (at the supply frequency, $50 \mathrm{~Hz}$ ) as well as other low-amplitude higher frequency harmonics contained in the signal. On the other hand, imf2 covers the frequency range below $50 \mathrm{~Hz}$. Hence, it reflects the evolution of all of the frequency components within that frequency band. If the machine is healthy, there are no relevant components in that band, therefore imf2 has negligible amplitude. When the machine has any broken damper bar, the LSC appears. As commented before, its frequency starts from $f(=50 \mathrm{~Hz})$, it drops to $0 \mathrm{~Hz}$ and increases again to near $f$. Thus, in this situation, the amplitude of imf 2 is no longer zero. Indeed, the waveform of imf 2 exactly reflects the theoretical shape of the LSC during the transient (depicted in Fig. 3 (a)). Therefore, the imf 2 resulting from the HHT of the startup current becomes a reliable indicator of the presence of the fault.

The HH spectrum of a certain imf is a time-frequency representation of that imf. Therefore, if the machine is faulty, the $\mathrm{HH}$ spectrum of the imf 2 resulting from the HHT of its startup current will reveal a clear V-shaped pattern in the timefrequency map. Logically, this pattern is caused by the frequency evolution of that $\mathrm{imf} 2$ (which further reflects the evolution of the LSC). Thus, the $\mathrm{HH}$ spectrum also constitutes a valid indicator of the presence of the failure; if the fault is present, the $\mathrm{V}$-shaped pattern will appear in the 2-D or 3-D image constituting the $\mathrm{HH}$ spectrum of imf2. Otherwise, if the machine is healthy, the pattern will be absent.

TABLE I MAIN CHARACTERISTICS OF THE TESTED MACHINES

\begin{tabular}{|c|c|}
\hline Rated power & $5 \mathrm{KVA}$ \\
\hline Rated voltage & $380 / 220 \mathrm{~V}(\mathrm{Y} / \Delta)$ \\
\hline Rated current & $7.5 / 13 \mathrm{~A}$ \\
\hline Number of phases & 3 \\
\hline Cos $(\varphi)$ & 0.8 \\
\hline Rated speed & $1500 \mathrm{rpm}$ \\
\hline Number of pole pairs & 2 \\
\hline Rated frequency & $50 \mathrm{~Hz}$ \\
\hline Insulation & Class B \\
\hline Maximum excitation voltage & $50 \mathrm{~V}$ \\
\hline
\end{tabular}




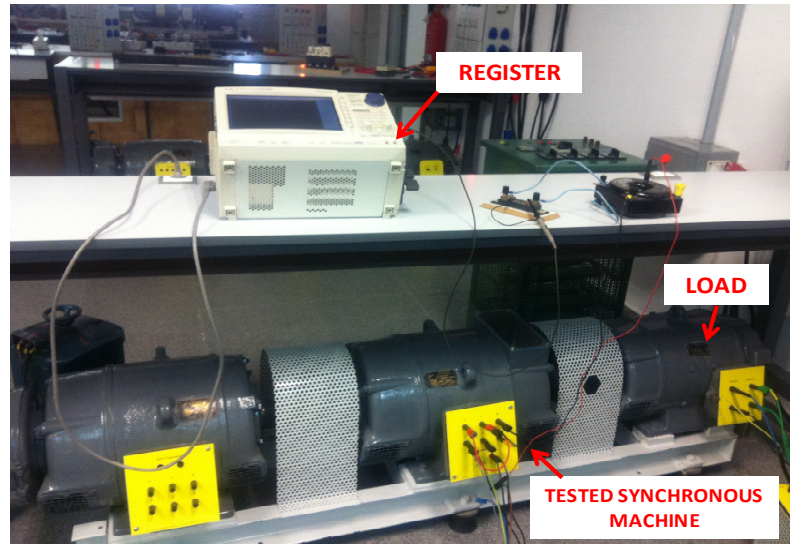

Fig. 5. Experimental test-bed

Figs. 6, 7 and 8 represent, respectively, the imf 2 waveform (a, top) and the marginal spectrum of the imf2 (a, bottom), the HH spectrum of the imf2 in 2-D (b) and the HH spectrum of the imf2 in 3-D (c) for the unloaded healthy machine (Fig. 6), unloaded machine with a low asymmetry (Fig. 7) and loaded machine with damaged damper (Fig. 8).

Analysis of the figures reveals that differences between the imf2s (a, top) of the three cases are obvious. In agreement with the previous comments, the imf 2 (which extracts the frequency components below $50 \mathrm{~Hz}$ ) remains with almost zero amplitude for the healthy machine (Fig. 6) and with very low amplitude for machine with low level of asymmetry (Fig. 7), whereas it has a significant amplitude for the faulty one (Fig. 8). In addition, in this latter case, its shape is in clear concordance with the theoretical evolution of the LSC depicted in Fig. 3(a) and justified in [15]. Hence, the imf $2 \mathrm{~s}$ are reliable indicators of the presence of the failure. The marginal spectrum, shown in section (a, bottom) of each figure is only a simple representation of the frequency content of each imf2. Logically, when the machine is faulty, the marginal spectrum of imf 2 reveals the presence of the frequencies below $50 \mathrm{~Hz}$, since these are the frequencies exhibited by the LSC in its trip during the startup.

On the other hand, visualization of the HH spectra (timefrequency representations of the imf2s) in the case of the faulty machine (Fig. 8) reveals a clear V-shaped pattern both in the 2-D (Fig. 8 (b)) and in the 3-D (Fig. 8(c)) plots of the HH spectrum. This pattern is caused by the frequency evolution of the LSC during the transient. Therefore, the $\mathrm{HH}$ spectrum also proves the existence of the LSC and, thus, the presence of the failure. Hence, this $\mathrm{HH}$ spectrum is also a good indicator for diagnosing the presence of the fault in the machine. Moreover, this representation has the additional advantage that it can be processed by image recognition techniques able to identify the $\mathrm{V}$-shaped pattern in an automatic way.

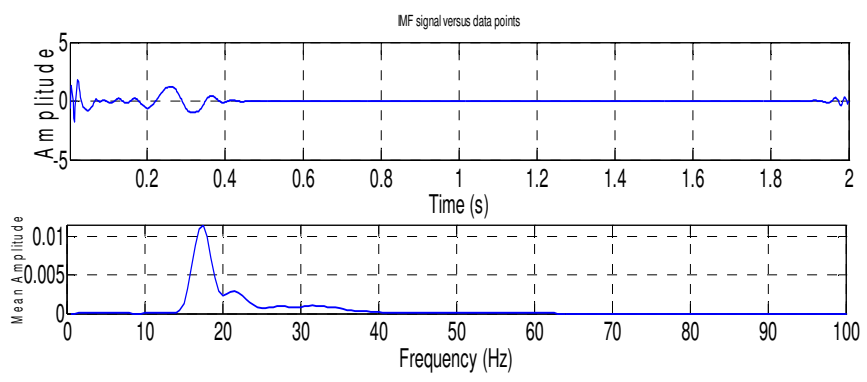

(a)

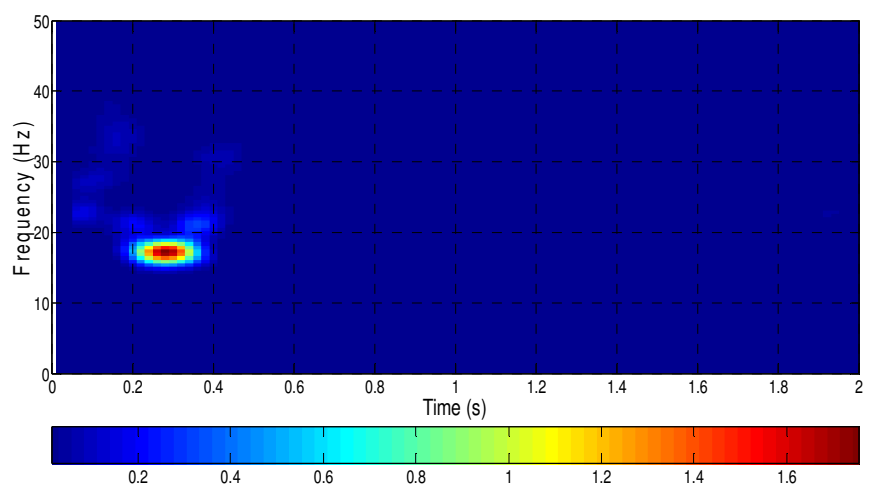

(b)

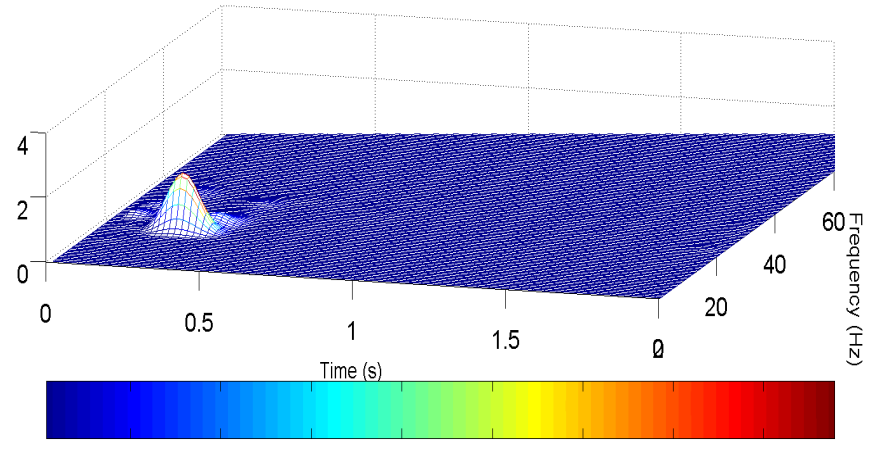

(c)

Fig. 6. Healthy machine (simulations): (a) waveform of the imf2 (top) and marginal spectrum of the imf2 (bottom), (b) 2-D Hilbert-Huang spectrum of the imf2 and (c) 3-D Hilbert-Huang spectrum of the imf2.

In the case of the machine with low level of asymmetry, the pattern is much less clear. However, certain traces of this $\mathrm{V}$ shape pattern are still noticeable (see Fig. 7(b) and (c)) revealing the existence of a certain asymmetry in the machine. Finally, the pattern is totally absent in the HH spectra of the healthy machine (Fig. 6 (b) and (c)). This is the logical situation in a synchronous motor with a healthy damper; since there are no significant components in the frequency band below $50 \mathrm{~Hz}$ (the LSC is absent), the imf 2 will have negligible amplitude and, therefore, its HH spectrum will not show any signature in its covered time-frequency region.

It must be said that initial oscillations appearing in the imf $2 \mathrm{~s}$ of all the analyzed cases are due to the electromagnetic transient (EMT) occurring always at the beginning of the any asynchronous startup regardless of the condition of the machine [15]. 


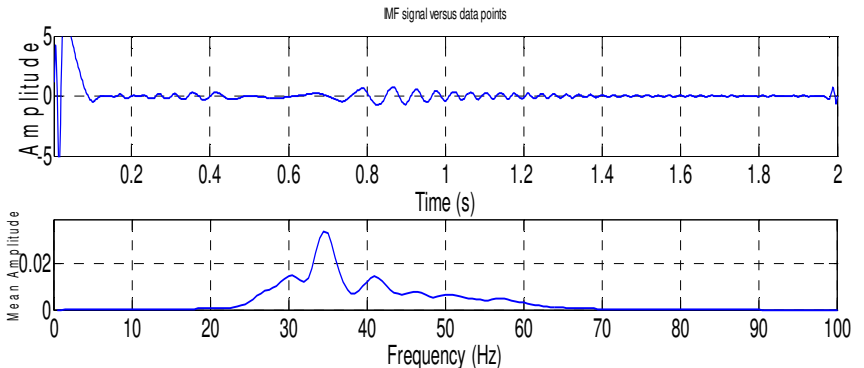

(a)

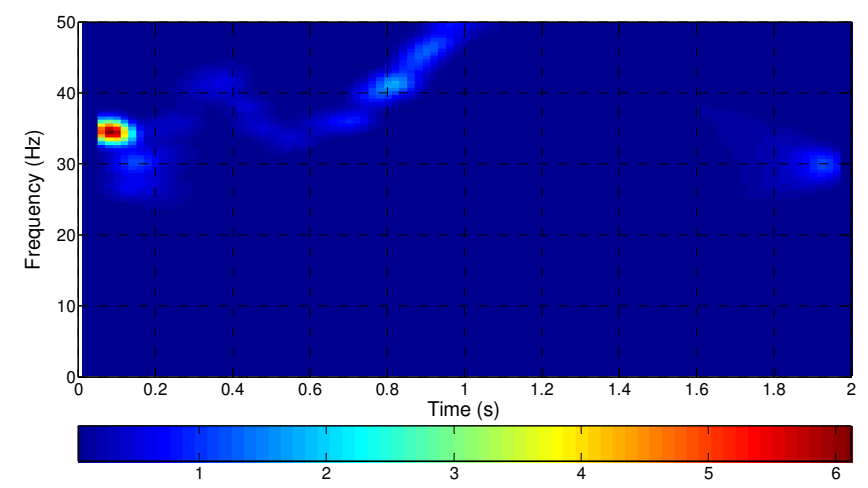

(b)

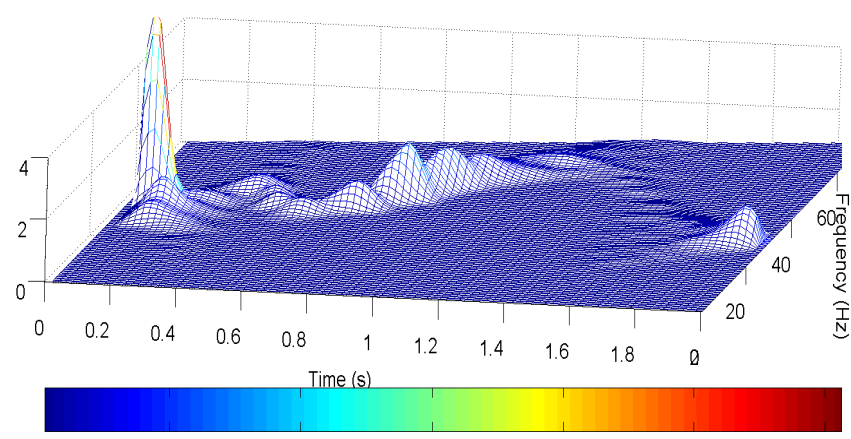

(c)

Fig. 8. Loaded synchronous machine 2 (higher asymmetry): (a) waveform of the imf2 (top) and marginal spectrum of the imf2 (bottom), (b) 2-D HilbertHuang spectrum of the imf2 and (c) 3-D Hilbert-Huang spectrum of the imf 2 .

\section{QUANTIFICATION PARAMETERS}

The described diagnostic approach is based on the qualitative identification either of characteristic V-shaped patterns in the time-frequency plots provided by the $\mathrm{HH}$ spectrum or of a particular shape in the imf 2 waveform. This approach must be complemented with a quantitative perspective, by introducing non-dimensional indicators able to quantify the degree of failure in the machine.
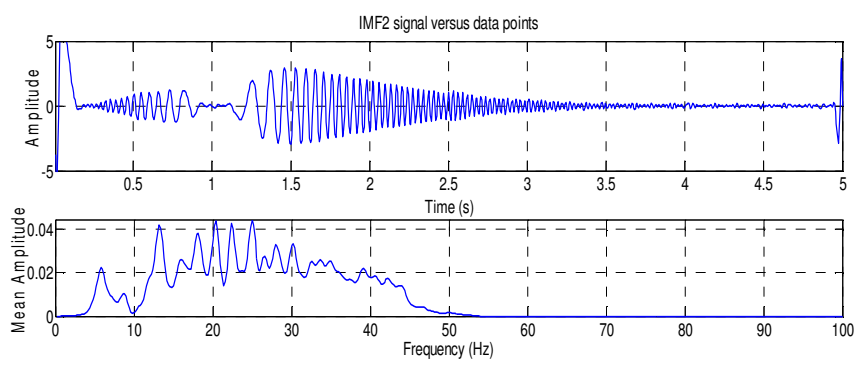

(a)

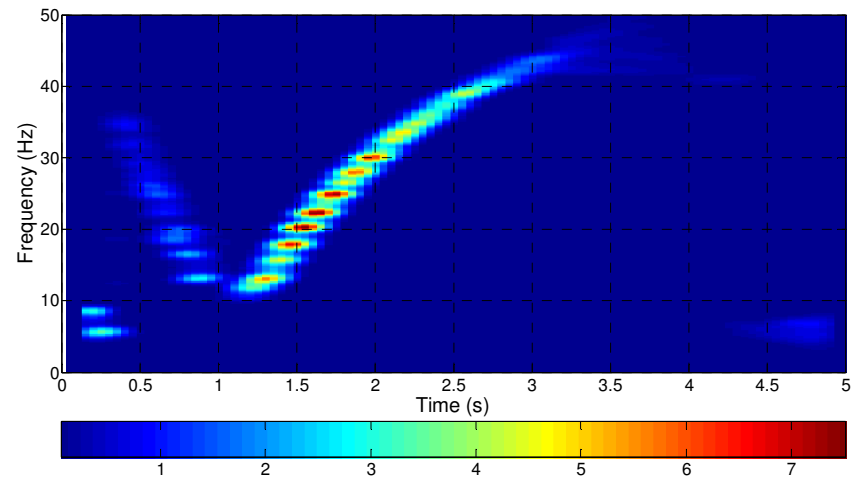

(b)

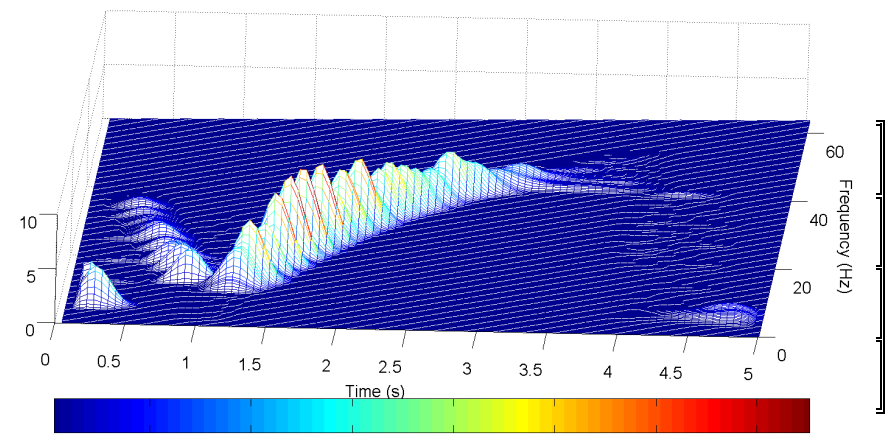

(c)

Fig. 7. Unloaded synchronous machine 1 (lower asymmetry): (a) waveform of the imf2 (top) and marginal spectrum of the imf2 (bottom), (b) 2-D Hilbert-Huang spectrum of the imf2 and (c) 3-D Hilbert-Huang spectrum of the imf 2 .

The HHT transient-based approach enables us to introduce such indicators. The fact that the amplitude (and hence the energy) of the imf 2 reflecting the transient evolution of the LSC is higher, the higher level of failure constitutes an excellent basis for the introduction of quantitative indicators based on the energy of that signal.

It is known that the energy $(E)$ of a discrete signal $f=\left(f_{1}, f_{2}\right.$, $\left.f_{3}, \ldots, f_{\mathrm{N}}\right) \in \mathrm{R}^{\mathrm{N}}$ is defined as the sum of the squares of its samples, according to (6).

$$
E(f)=f_{1}^{2}+f_{2}^{2}+\ldots+f_{N}^{2}
$$


Then, a preliminary quantification indicator might be introduced, based on the energy of the imf2. This indicator should be defined so that it remains independent of the duration of the startup transient, loading conditions or inertia. This could be achieved by relating the energy of the imf 2 to the energy of the startup current signal, according to the expression (7).

$$
\gamma_{H H T}(d B)=10 \cdot \log \left[\frac{\sum_{j=N b}^{N s} i_{j}^{2}}{\sum_{j=N b}^{N s}[i m f 2(j)]^{2}}\right]
$$

where $i_{j}$ is the value of the $j$ sample of the current signal; $\operatorname{imf} 2(j)$ is the $j$ element of the $i m f 2$ signal covering the frequency range in which the LSC evolves during the startup transient; $N_{s}$ is the number of samples of the signal, until reaching the steady-state regime and $N_{b}$ is the number of samples between the origin of the signals and the extinction of the oscillations due to border effects.

According to its definition, the lower the level of failure is, the higher the value of the parameter $\gamma_{H H T}$. Table II shows the results obtained when computing this parameter for the previous machines, i.e., simulated healthy machine and real laboratory machines with different levels of asymmetry.

TABLE II COMPUTATION OF QUANTIFICATION PARAMETER

\begin{tabular}{|c||l||c||c||}
\hline Machine & Condition & $\boldsymbol{\gamma}_{\boldsymbol{H H T}}(\boldsymbol{d B})$ & $\Delta \boldsymbol{\gamma}_{\boldsymbol{H} T}$ \\
\hline \hline $\begin{array}{c}\text { Synchronous machine } \\
\text { (simulations) }\end{array}$ & Healthy & 90.2819 & - \\
\hline \hline $\begin{array}{c}\text { Laboratory synchronous } \\
\text { machine 1 }\end{array}$ & $\begin{array}{l}\text { Low } \\
\text { asymmetry }\end{array}$ & 86.6478 & 3.6341 \\
\hline \hline $\begin{array}{c}\text { Laboratory synchronous } \\
\text { machine 2 }\end{array}$ & $\begin{array}{l}\text { Significant } \\
\text { asymmetry }\end{array}$ & 61.6986 & 28.5833 \\
\hline
\end{tabular}

Clear differences in the value of the parameter are detected for different levels of asymmetry. The parameter slightly changes between a healthy machine and a machine with low asymmetry (near $4 \mathrm{~dB}$ ), showing a much higher variation with respect significant asymmetry condition (almost $30 \mathrm{~dB}$ ). This high sensitivity confirms that this indicator could be valid for quantifying the severity of the failure complementing the qualitative approach based on pattern detection.

The use of the energies of the imf 2 signals instead of using their amplitudes provides the advantage of attenuating the effect of possible perturbations that can be present in the industrial environment and that might distort the amplitude of these signals. Since the energy of the $\operatorname{imf} 2 \mathrm{~s}$ is equivalent to integration along the considered interval of the signal, the effects of these possible phenomena are attenuated, increasing the reliability of the quantification parameter.
Therefore, the application of the proposed diagnosis methodology is in two steps:

- First, apply the HHT to the startup current and identify the characteristic V-shaped pattern in the $\mathrm{HH}$ spectrum or of the particular waveform in the imf2. This stage identifies the presence or absence of the fault.

- Second, compute the quantification indicator $\gamma_{H H T}$ based on the energy of the imf 2 and startup current signal. This step determines the level of severity of the failure.

The two stage process described above increases the reliability of the approach, while not requiring higher computational expenses due to the simplicity and low operational costs both of the HHT and of the defined indicator.

In any case, further tests should be performed in synchronous machines with different sizes and damper conditions in order to obtain accurate ranges for the proposed parameters associated with different levels of damper failure. These would make possible the automatic determination of the degree of failure in the machine, once the fault has been identified.

\section{CONCLUSIONS}

The HHT, based on the EMD method, is applied in this paper to diagnose the presence of broken damper bars in synchronous motors.

This paper has remarked on the importance of condition monitoring of such an element in synchronous machines, providing various references reporting failures in damper windings of synchronous motors and generators.

The proposed technique takes advantage of the fact that significant currents flow through the damper winding only during transient operation of the machine. If the damper cage is broken, fault-related components will appear in the stator current. Transient tracking of those components by using proper TFD tools provides conclusive information for the diagnosis of the fault.

The proposed technique is based on a double perspective: qualitative (recognition of characteristic patterns) plus quantitative (computation of non-dimensional parameters for quantifying the severity of the fault). It presents important advantages in comparison with FFT analysis of steady-state current; first, because in steady-state operation no significant currents flow through the damper cage and, therefore, no significant components are induced in the stator winding. Second, because, even if the steady-state current is captured before feeding the field winding, the FFT technique would not be able to detect the fault-related peaks in light-loaded or unloaded conditions.

\section{REFERENCES}

[1] H.W. Beaty, J.L. Kirtley, Jr. Electric Motor Handbook, McGraw-Hill Book Company, 1998, Ch. 5, Pg. 157.

[2] H.A. Toliyat, G.B. Kliman, Handbook of Electric Motors. Marcel Dekker Inc, 2004, ch.5.

[3] H.C. Karmaker and M. Chunting, "Improving the starting performance of large salient-pole synchronous machines", IEEE Transactions on Magnetics, Vol. 40, no. 4, July 2004, pp. 1920-1928. 
[4] J. Bacher, "Detection of Broken Damper Bars of a Turbo Generator by the Field Winding.", Renewable Energy and Power Quality Journal, no. 2, April 2004.

[5] M.M. Rahimian, K. Butler-Purry, "Modeling of synchronous machines with damper windings for condition monitoring," in Proc. of IEEE International Electric Machines and Drives Conference, 2009. IEMDC '09, pp.577-584, 3-6 May 2009.

[6] H. C. Karmaker, "Broken Damper Bar Detection Studies Using Flux Probe Measurements and Time-Stepping Finite Element Analysis for Salient-Pole Synchronous Machines," in Proc. Symposium on Diagnostics for Electric Machines, Power Electronics and Drives, pp. 193-197, August 2003

[7] P. Neti, A.B. Dehkordi,A.M. Gole, "A New Robust Method To Detect Rotor Faults in Salient-Pole Synchronous Machines Using Structural Asymmetries," Industry Applications Society Annual Meeting, 2008. IAS '08. IEEE, vol., no., pp.1-8, 5-9 Oct. 2008.

[8] V.V. Kuzmin, A.N. Vakulenko, "Hydrogenerator poles damageby electrical erosion-pattren cause, diagnostics and failure prevention" in Proc. of CIGRE SESSION 2006, Zagreb 2006.

[9] G. Ebi, "Ageing generator rotor: Refurbishment or removal from service?" Power Engineering International Magazine, vol. 17, no.5 May 2009

[10] A. Schwery, "Large Hydro Generators. Experience and References," CIGRE session 2008, Paris.

[11] K. Celic, M. Dadic and V. Vrzic, "Stator Damper Winding and Electromagnetic Parameters of Turbogenerators," in Proc. 2010 IEEE International Conference on Industrial Technology (ICIT), pp. 416-421, 14-17 March, 2010.

[12] M. Xianhao, D. Shuye, L.Weili, "Calculation and Analysis of Magnetic Fields and Temperature Fields for Salient Pole Synchronous Motors in the Process of Starting," in Proc. 2006 International Conference on Power System Technology (PowerCon), pp.1-6, 22-26 Oct. 2006

[13] J. A. Antonino-Daviu, M. Riera-Guasp, J. R. Folch, and M. Pilar Molina Palomares, "Validation of a new method for the diagnosis of rotor bar failures via wavelet transform in industrial induction machines," IEEE Trans. Ind. Applications, vol. 42, pp. 990-996, 2006.

[14] M. Riera-Guasp, J. A. Antonino-Daviu, M. Pineda-Sanchez, R. PuchePanadero, and J. Perez-Cruz, "A General Approach for the Transient Detection of Slip-Dependent Fault Components Based on the Discrete Wavelet Transform," IEEE Transactions Industrial Electronics, vol. 55, pp. 4167-4180, 2008

[15] M. Riera-Guasp, J. A. Antonino-Daviu, J. Roger-Folch, and M. P. Molina Palomares, "The Use of the Wavelet Approximation Signal as a Tool for the Diagnosis of Rotor Bar Failures," IEEE Trans. Ind. Applications, vol. 44, pp. 716-726, 2008.

[16] W. G. Zanardelli, E. G. Strangas, and S. Aviyente, "Identification of Intermittent Electrical and Mechanical Faults in Permanent-Magnet AC Drives Based on Time-Frequency Analysis," IEEE Trans. Ind. Appl., vol. 43, pp. 971-980, 2007.

[17] H. Douglas, P. Pillay, and A. Ziarani , "Broken rotor bar detection in induction machines with transient operating speeds," IEEE Transactions on Energy Conversion, vol. 20, no. 1, pp. 135-141, March 2005.

[18] A.Ordaz-Moreno, R.Romero-Troncoso, J.A.Vite-frías, J.RivieraGillen, A.García-Pérez, "Automatic online diagnostic algorithm for broken-bar detection on induction motors based on Discrete Wavelet Transform for FPGA implementation", IEEE Transactions on Industrial Electronics, , vol.55, no.5, pp.2193-2200, May. 2008

[19] S.H. Kia, H. Henao and G.A. Capolino, "Diagnosis of Broken-Bar Fault in Induction Machines Using Discrete Wavelet Transform Without Slip Estimation," IEEE Transactions on Industry Applications, Vol. 45, No. 4, July/August 2009, pp. 1395-1404.

[20] W.G. Zanardelli, E.G. Strangas,H.K. Khalil, J.M. Miller "Wavelet-based methods for the prognosis of mechanical and electrical failures in electric motors", Mechanical Systems and Signal Processing. Elsevier. No. 19, 2005. pp. 411-426

[21] F. Briz, M.W. Degnert, P. Garcia, D. Bragado, "Broken rotor bar detection in line-fed induction machines using complex wavelet analysis of startup transients," IEEE Transactions on Industry Applications, Vol. 44, No. 3, May-June 2008, pp. 760-768.

[22] S. Rajagopalan, J.M. Aller, J.A. Restrepo, T.G. Habetler and R.G. Harley, "Analytic-Wavelet-Ridge-Based Detection of Dynamic Eccentricity in Brushless Direct Current (BLDC) Motors Functioning
Under Dynamic Operating Conditions", IEEE Transactions on Industrial Electronics, vol. 54, no. 3, pp. 1410-1419, June 2007.

[23] J. Cusido, L. Romeral, J.A. Ortega, J.A. Rosero, A. Garcia Espinosa, "Fault Detection in Induction Machines Using Power Spectral Density in Wavelet Decomposition," IEEE Transactions on Industrial Electronics, vol.55, no.2, pp.633-643, Feb. 2008

[24] J.A. Antonino-Daviu, M. Riera-Guasp, M. Pineda-Sánchez, R.B. Pérez, "A Critical Comparison Between DWT and Hilbert-Huang-Based Methods for the Diagnosis of Rotor Bar Failures in Induction Machines", IEEE Transactions on Industry Applications, Volume 45, Issue 5, Sept.-oct. 2009 Page(s):1794 - 1803.

[25] Z.K. Peng, P.W. Tse, F.L. Chu, "A Comparison Study of Improved Hilbert-Huang Transform and Wavelet Transform: Application to Fault Diagnosis for Rolling Bearing", Mechanical Systems and Signal Processing, Elsevier, Vol. 19, 2005, pp. 974-988.

[26] V.K. Rai, A.R. Mohanty, "Bearing Fault Diagnosis using FFT of intrinsic mode functions in Hilbert-Huang transform," Mechanical Systems and Signal Processing, Elsevier, Vol. 21, No. 6, August 2007, pp. 2607-2615.

[27] M. Blodt, D. Bonacci, J. Regnier, M. Chabert, and J. Faucher, "On-Line Monitoring of Mechanical Faults in Variable-Speed Induction Motor Drives Using the Wigner Distribution," IEEE Trans. Ind. Electron., vol. 55, pp. 522-533, 2008.

[28] S. Rajagopalan, J.M. Aller, J.A. Restrepo, T.G. Habetler, R.G. Harley, "Detection of Rotor Faults in Brushless DC Motors Operating Under Nonstationary Conditions," IEEE Transactions on Industry Applications, vol.42, no.6, pp.1464-1477, Nov-Dec. 2006.

[29] G.B. Kliman, "Transient rotor fault detection in induction and synchronous motors," U.S. Patent 5030 917, July 9, 1991.

[30] W.Deleroi "Broken bar in a squirrel-cage rotor of an induction motor Part 1: Description by superimposed fault-currents", Archiv für Elektrotechnik $\mathrm{n}^{\circ} 67$ (1984). pp. 91-99.

[31] G.B Kliman, J Stein, and R.D. Endicott, "Noninvasive Detection of Broken Rotor Bars in Operating Induction Motors," IEEE Transactions on Energy Conversion, vol. 3, no. 4, pp. 873-879, December 1988.

[32] N.M. Elkasabgy, A. R. Eastham, and G. E. Dawson, "Detection of broken rotor bars in the cage rotor on an induction machine," IEEE Transactions Industry Applications., vol. 28, no. 1, pp. 165-171, Jan./Feb. 1992.

[33] M. H. Benbouzid, "A review of induction motors signature analysis as a medium for faults detection" IEEE Transactions on Industrial Electronics, Vol. 47, No. 5, October 2000.

[34] F. Filippetti, G. Franceschini, C. Tassoni, P. Vas, "Recent developments of induction motor drives fault diagnosis using AI techniques", IEEE Transactions on Industrial Electronics, Vol. 47, No. 5, October 2000, pp 994-1004.

[35] F. Filippetti, G. Franceschini, C. Tassoni, P. Vas, "AI techniques in induction machines diagnosis including the speed ripple effect", IEEE Transactions on Industry Applications, Vol. 34, No. 1, January/february 1998, pp 98-108.

[36] N.E. Huang, S.S.P Shen, Hilbert-Huang Transform and its Applications. World Scientific Publishing, 2005.

[37] N.E. Huang, Z. Shen, S.R. Long, M.C. Wu, H.H. Shih, Q.Zheng N.C. Yen,C.C. Tung and H.H. Liu, "The Empirical Mode Decomposition and the Hilbert Spectrum for Nonlinear and Nonstationary Time Series Analysis", Proc. Royal Society of London, A, vol. 454, pp. 903-995, 1998.

[38] D. Gabor, "Theory of Communication," J. IEE, vol. 93, no. 26, pp. 429457, November 1946.

[39] D. Yu, J. Cheng and Y. Yang, "Application of EMD method and Hilbert spectrum to the fault diagnosis of roller bearings", Mechanical Systems and Signal Processing, Elsevier, Vol. 19, 2005, pp. 258-270.

[40] M. Pineda-Sánchez, J. Roger-Folch, J. Pérez-Cruz, M. Riera-Guasp, R. Puche-Panadero, J. Antonino-Daviu, J. Pons-Llinares, "Calculation of Winding Inductances via Magnetic Vector Potential, Discrete Convolution and Fast Fourier Transform", Przeglad Elektrotechniczny (Electrical Review), Volume 5, 2010, pp. 109 - 113. 


\section{BIOGRAPHIES}

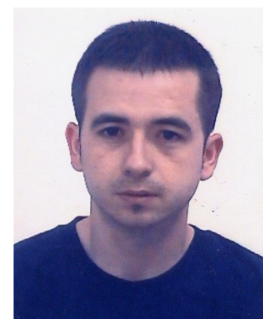

Jose A. Antonino-Daviu received the M.Sc. degree in Electrical Engineering from the Universidad Politecnica de Valencia in 2000 and the Ph.D. degree in Electrical Engineering in 2006. He worked in the private sector, being involved in several international projects. Currently, he is Associate Professor in the Faculty of Industrial Engineering of the mentioned University, where he develops his docent and research work. He was an invited professor in Helsinki University of Technology (Finland) in 2005 and 2007 and in Michigan State University (USA) in 2010. His primary research interests are condition monitoring of electric machines, wavelet theory and its application to fault diagnosis and design and optimization of electrical installations and systems.

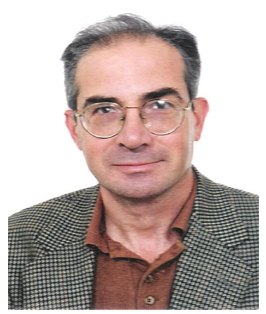

Martín Riera-Guasp received the M.Sc. degree in Industrial Engineering and the Ph.D. degree in Electrical Engineering from the Polytechnic University of Valencia (Spain) in 1981 and 1987, respectively. Currently he is an Associate Professor in the Department of Electrical Engineering of the Polytechnic University of Valencia. His research interests include condition monitoring of electrical machines, applications of the Wavelet Theory to electrical engineering and efficiency in electric power applications.

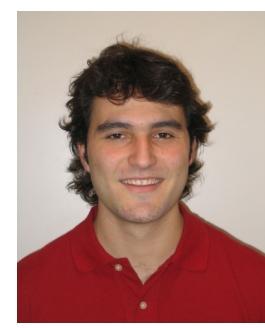

Joan Pons Llinares received the M.Sc. degree in Industrial Engineering (Electrical Speciality) from the Universitat Politècnica de València (UPV, Spain) in 2007. In 2005, he started working as a researcher in the Department of Electrical Engineering of the UPV. At first, he worked in the domain of Distribution losses. He did some research works about Overvoltages and Space Phasors too and had a short time period work in the private sector. After obtaining the M.Sc. degree, he focused his research interests in the Wavelet Theory and its applications to fault diagnosis of electrical machines. He is currently pursuing the Ph.D. degree.

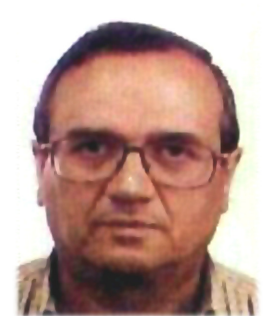

José Roger Folch obtained his M.Sc. degree in Electrical Engineering in 1970 from the Polytechnic University of Cataluña and his $\mathrm{Ph} . \mathrm{D}$ in 1980 from the Polytechnic University of Valencia, Spain. From 1971 to 1978 he worked in the Electrical Industry as Project Engineer. Since 1978, he joined the Polytechnic University of Valencia and he is currently Professor of Electrical Installations and Machines. His main research areas are the Numerical Methods (F.E.M. and others) applied to the Design and Maintenance of Electrical Machines and Equipments.

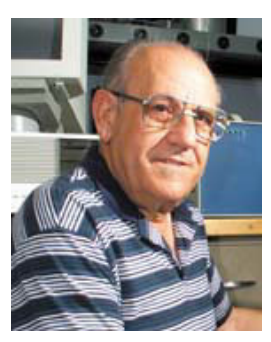

Rafael B. Pérez is Master in Chemistry from University of Valencia (1951), Master in Nuclear Engineering from MIT (Massachusets Institute of Technology) (1958) and $\mathrm{PhD}$ in Physics from University of Madrid (1961).

$\mathrm{He}$ has worked for: Spanish Air Force Meteorology Officer (1948-1955); Junta de Energia Nuclear (Spain) (1955-1961); Associate Professor of Nuclear Engineering University of Florida (1961-1967); Senior Research Scientist Oak Ridge National Laboratory (ORNL) (1967-1980), Full Professor of Nuclear Engineering University of Tennessee (UTK) (1980 - 1997).

Presently, he is Emeritus Professor of UTK He has over 200 reviewed papers on signal analysis, nuclear reactor dynamics, quantum mechanics and neutron cross section theory.

He is Fellow of the American Nuclear Society (ANS); in 1999 he was awarded with the ANS Wigner Prize.

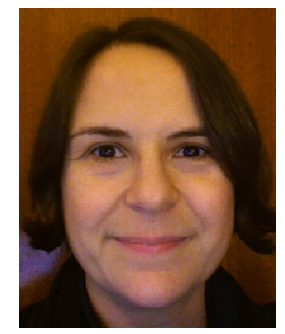

Cristina Charlton-Perez received her Ph.D. in Applied Mathematics from the University of Colorado, Boulder in 2003. She has completed two post-docs in Atmospheric Science, one at Columbia University, NY and at then at the University of Leeds, UK. Currently, Dr. Charlton-Perez is a senior scientist at the UK Meteorological Office working on highresolution data assimilation problems in atmospheric science. 